\section{CD30+ primary cutaneous post-transplant lymphoproliferative disorder with signet-ring cell features}

\author{
Neeta Malviya, Heather Wickless \\ Department of Dermatology, University \\ of Texas Southwestern Medical Center, \\ Dallas, TX, USA
}

\section{Abstract}

We report a case of primary cutaneous CD30+ post-transplant lymphoproliferative disorder with an uncommon finding of signet ring cell features in a heart transplant patient. The neoplastic cells were CD4 and CD30 positive, and negative for S-100, pancytokeratin, myeloperoxidase, and CD56. In situ hybridization for Epstein Barr Virus (EBV) was negative, even though the patient did have EBV viremia.

\section{Introduction}

Post-transplant lymphoproliferative disorder (PTLD) is a common complication of chronic immunosuppression in adult solid organ transplant patients with an incidence as high as $10 \%$. More than $80 \%$ of PTLD are B-cell malignancies associated with Epstein Barr Virus (EBV). Only about 15\% of PTLD are T-cell malignancies, and only 1 out of 5 of these are associated with EBV. ${ }^{1}$ This report describes a unique case of a cutaneous CD30+ T-cell PTLD with signet ring features that developed in a heart transplant patient.

\section{Case Report}

A 64-year-old male, two years status-post orthotopic heart transplant for ischemic cardiomyopathy, presented with an agminated cluster of deep red-to-brown firm, indurated erythematous nodules on his left hip and groin (Figure 1). The patient's immunosuppressive medications included mycophenolate sodium $1440 \mathrm{mg}$ and cyclosporine $175 \mathrm{mg}$. He had no constitutional symptoms at the time. The patient was referred to dermatology for evaluation, and the lesions on his left buttock and hip were biopsied (Figure 2). Pathology results showed a diffuse interstitial infiltrate of atypical lymphoid cells that were large and pleomorphic with mitotic figures. Immunohistochemistry staining of the atypical cells was positive for CD4 and CD30. Stains for S-100, pancytokeratin, myeloperoxidase, and CD56 were negative. The biopsy was consistent with a CD30+ lymphoproliferative disorder. A PETCT was done and was negative for nodal disease or other foci beyond the primary lesions on the hip. Flow cytometry and T-cell rearrangement studies were performed on the patient's blood. These results were negative for clonality and only notable for a depressed CD4 to CD8 ratio. Given these findings, immunosuppression was reduced with mycophenolate sodium decreased to $360 \mathrm{mg}$ and prednisone $7.5 \mathrm{mg}$ /day was added. The patient underwent radiation therapy with a total of $4600 \mathrm{~Gy}$ of radiation to the affected area. However, during the course of radiation, he developed new lesions in his left popliteal fossa and ankle. His immunosuppressive regimen could not be lowered further due to risk of graft rejection. A repeat biopsy was performed of the newly developing lesions. This also showed a CD30+ lymphoproliferative disorder with signet ring cell features (Figure 3). The dermis contained a dense infiltrate of enlarged mononuclear cells organized in nodules, cords, and strands embedded in a sclerotic stroma. No lymphocytes were highlighted by CD20 and in situ hybridization for EBV was negative. However, the patient did have an EBV viremia with a titer of 6398 one month prior to the onset of the lesions. Due to the multifocal nature of these newly-developing scattered smaller lesions, the decision was made to treat with the addition of methotrexate $15 \mathrm{mg} /$ week. The larger plaques resolved following local radiation treatment at a follow-up visit three months after initial radiation therapy. The smaller lesions on the left popliteal fossa and ankle remained stable with the addition of methotrexate.

\section{Discussion and Conclusions}

Post-transplant lymphoproliferative disorders are hematologic malignancies arising as a product of chronic immunosuppression. ${ }^{2}$ PTLDs are more common following heart and lung transplants. ${ }^{2}$ The median time interval between transplant and the diagnosis of cutaneous PTLD is approximately 5 years. ${ }^{2,3}$ However, approximately 15\% of T-cell PTLDs occur within one year of transplant. ${ }^{4}$ Early presentation of PTLDs tends to be associated with EBV, though this was not the case our presented patient. ${ }^{3}$

The morphology and phenotype of posttransplant T-cell malignancies are highly variable. Compared with B-Cell PTLDs, T-Cell PTLDs are more likely to present later, less likely to be EBV positive, and less likely to involve the transplanted organ. ${ }^{4}$ However,
Correspondence: Heather Wickless, Department of Dermatology, University of Texas Southwestern Medical Center, 5323 Harry Hines Blvd, Dallas, TX 75390, USA.

Tel.: +1.214.648.4229 - Fax: + 1.214.648.5553.

E-mail: heather.wickless@UTSouthwestern.edu

Key words: Signet-ring cell; CD30; post-transplant lymphoproliferative disorder.

Contributions: the authors contributed equally.

Conflict of interest: the authors declare no potential conflict of interest.

Received for publication: 27 January 2016. Accepted for publication: 8 June 2016.

This work is licensed under a Creative Commons Attribution-NonCommercial 4.0 International License (CC BY-NC 4.0).

(C) Copyright N. Malviya and H.Wickless, 2016

Licensee PAGEPress, Italy

Hematology Reports 2016; 8:6433

doi:10.4081/hr.2016.6433

there are reported cases of post-transplant CD30+ anaplastic large cell lymphoma (ALCL) associated with EBV. ${ }^{5}$ Regardless, as in the case of our patient, the pathogenesis of CD30+ T-cell lymphoma can occur independent of EBV. CD30+ cutaneous lymphoproliferative disorders encompass the second most common form of cutaneous lymphomas according to the World Health Organization and European Organization for Research and Treatment of Cancer Classification (WHO-EORTC). ${ }^{6}$ Lymphomatoid papulosis and ALCL form the spectrum of CD30 + cutaneous disease and distinguishing the two is based on clinical grounds. According to the WHO-EORTC, the histological criteria for lymphomatoid papulosis type $\mathrm{C}$ includes a nodular infiltrate with sheets of large atypical lymphoid cells and the differential includes CD30+ ALCL. Our patient presented with lesions most consistent with ALCL as they were fixed and did not spontaneously resolve, despite having multiple lesions. No curative treatment is currently available for cutaneous CD30+ PTLDs. Doxycycline, low-dose methotrexate, topical steroids, and radiation are commonly used treatments for lymphomatoid papulosis whereas localized radiation therapy is the treatment of choice for CD30+ ALCL. ${ }^{6}$

CD30+ cutaneous T-cell lymphoma in posttransplant patients presents in a similar manner as in non-transplant patients with a solitary ulcerating nodule or a cluster or nodules or papules in a single region. ${ }^{7}$ The histological features are also classic to the cutaneous T-cell lymphomas seen in the general population. ${ }^{2}$ 
The clinical behavior of primary cutaneous Tcell lymphomas is similar in transplant and non-transplant patients. ${ }^{7}$

Additionally, this case had a unique feature of signet ring cells in the histologic findings. ${ }^{8}$ In cases of cutaneous signet cell $\mathrm{T}$ cell lymphoma that have been previously noted, multivesicular bodies have been thought to be the reasoning behind the signet ring appearance. ${ }^{9}$ It is postulated that signet ring cell formation is the result of membrane recycling. ${ }^{10}$ The exact cause of this histologic characteristic still remains unknown, and this case serves to add signet ring features to the histological spectrum of primary cutaneous PTLD.

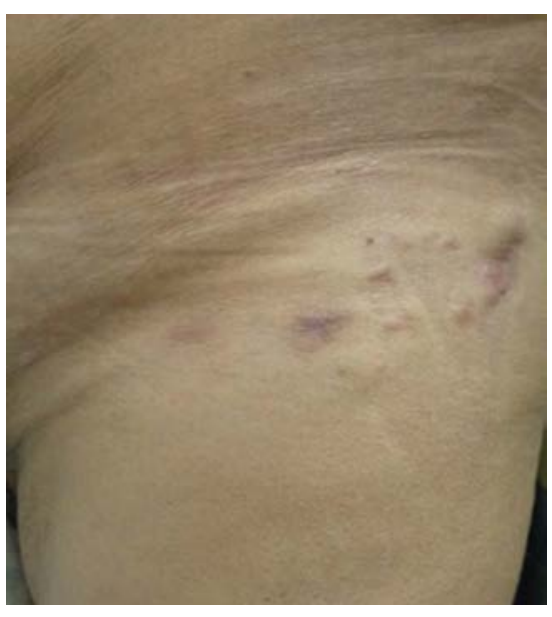

Figure 1. Cluster of deep red-to-brown firm, indurated erythematous nodules on the left upper thigh.

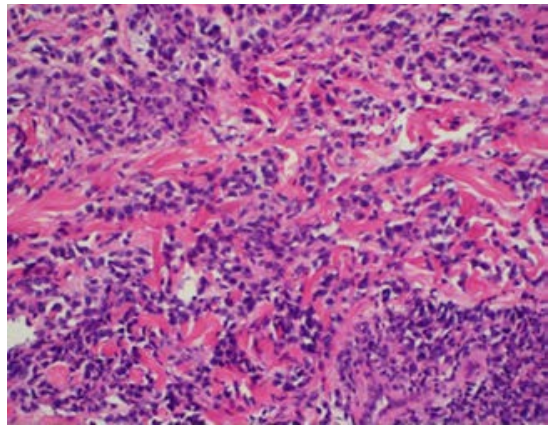

Figure 2. Left hip biopsy showing a diffuse interstitial infiltrate of large atypical lymphoid cells displaying pleomorphic features with mitotic figures.

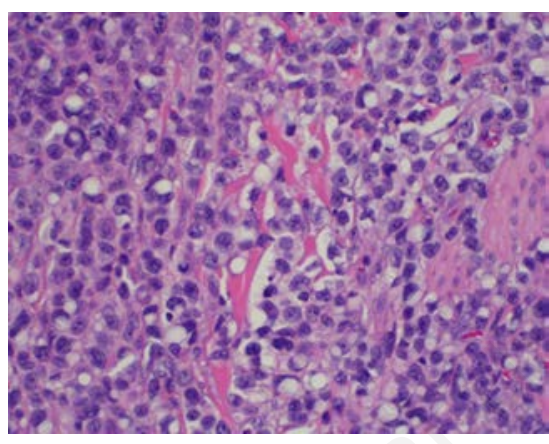

Figure 3. Biopsy from left medial thigh showing signet ring cell morphology.

\section{References}

1. Parker A, Bowles K, Bradley JA, et al. Diagnosis of post transplant lymphoproliferative disorder in solid organ transplant recipients: BCSH and BTS Guidelines. Br J Haematol 2010;149:675-92.
2. Seckin D, Barete S, Euvrard S, et al. Primary cutaneous post-transplant lymphoproliferative disorders in solid organ transplant recipients: a multicenter European case series. Am J Transplant 2013;13:2146-53.

3. Swerdlow SH. T-cell and NK-cell posttransplantation lymphoproliferative disorders. Am J Clin Pathol 2007;127:887-95.

4. Lucioni M, Ippoliti G, Campana C, et al. EBV positive primary cutaneous CD30+ large T cell lymphoma in a heart transplanted patient: case report. Am J Transplant 2004;4:1915-20.

5. Cordoba A, Querol I, Monzon FJ, et al. Lymphomatoid papulosis associated with cutaneous T-cell signet ring lymphoma. Int J Surg Pathol 1998;6:165-70.

6. Querfeld C, Kuzel TM, Guitart J, Rosen ST. Primary cutaneous CD30+ lymphoproliferative disorders: new insights into biology and therapy. Oncology 2007;21:689-96.

7. Lok C, Viseux V, Denoeux JP, Bagot M. Post-transplant cutaneous T-cell lymphomas. Crit Rev Oncol Hematol 2005;56:137-45.

8. Papalas JA, Kulbacki EL, Park HK, Howell ER. Signet ring cell primary cutaneous CD30+ lymphoproliferative disorder presenting as a monomorphic T-cell posttransplant lymphoproliferative disease. Am J Dermatopathol 2012;34:e94-6.

9. Cross PA, Eyden BP, Harris M. Signet ring cell lymphoma of T cell type. J Clin Pathol 1989;42:239-45.

10. Grogan TM, Richter LC, Payne CM, Rangel CS. Signet-ring cell lymphoma of T-cell origin: an immunocytochemical and ultrastructural study relating giant vacuole formation to cytoplasmic sequestration of surface membrane. Am J Surg Pathol 1985;9:684-92. 